\title{
FULL TIME STUDENTS INVITED TO ENTER ESSAY COMPETITION
}

The Committee of the Association of Basic Science Teachers in Dentistry (ABSTD) is holding an essay prize competition for all students in full time programmes related to dentistry and oral health, with a first prize equivalent to $€ 1,000$.

The competition is to encourage interest in and engagement with basic sciences. The title of the essay for the competition, which has been chosen by the committee, is:

'Discuss how new technology is paving the way for personalised dentistry'.

Entries should be a reflective analysis of the topic within the scope of the basic and applied sciences which underpin dentistry. Entries should demonstrate integration of knowledge from across a range of relevant scientific disciplines, must reflect an understanding of contemporary scientific advances and be supported by reference to the appropriate literature.

Entries should be submitted to Jon Bennett, President of ABSTD, as a Word document to jon.bennett@plymouth.ac.uk, by Friday 31 March 2017.

Entrants are advised to read the competition regulations at www.abstd.org.

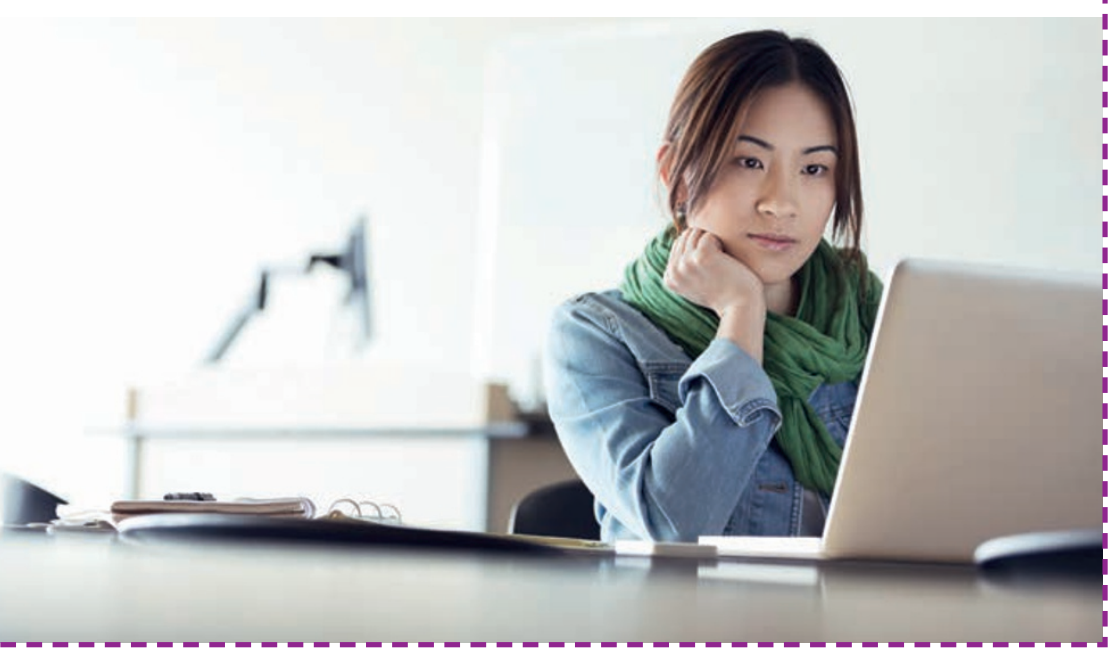

\section{FIRST INSURANCE SPECIFICALLY FOR DENTAL HYGIENISTS AND THERAPISTS LAUNCHED}

The British Society of Dental Hygiene and Therapy (BSDHT) has launched BSDHT Indemnity, a new insurance policy developed especially for dental hygienists and dental therapists.

This product is unique in the market as it is the only policy in the UK specifically for hygienists and therapists. Usually insurance policies include dentists, who typically have a higher exposure of risk and therefore increase the chances of a higher premium.

BSDHT Indemnity is an exclusive offering for BSDHT members and can be purchased at any point in the year. This bespoke policy has been designed by the BSDHT and Howden, a Chartered insurance broker with a specialist Care and Medical team.

Helen Minnery, President of BSDHT, said: 'Indemnity is such an important requirement within healthcare and dentistry, but to be truly effective that protection must be tailored to an individual's needs. The BSDHT have a longstanding reputation for representing the best interests of practising dental hygienists and those dually qualified in dental hygiene and therapy; by launching this bespoke insurance plan we want our members to feel both confident and reassured that there is policy that is specifically built for them.

'Being a low exposure and low risk group, it's unfair for dental hygienists and dental therapists to have to incur the higher premiums of typical insurance policies and BSDHT Indemnity seeks to correct this.'

Visit www.bsdht.org.uk for more information.

\section{Demtal}

\section{murse spots} fake dental device

Dental nurse Lizzie Boon was the winner of the 'Spot the Fake' competition held at BDIA Dental Showcase at ExCeL London in October.

The competition

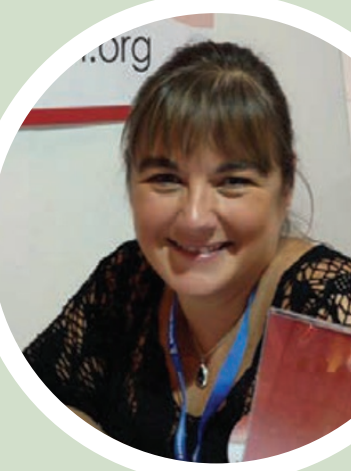
challenged members of the dental team to correctly identify genuine and counterfeit dental devices as part of the BDIA's award winning Counterfeit and Substandard Instruments and Devices Initiative (CSIDI), which has recently partnered with the Medicines and Healthcare products Regulatory Agency (MHRA) to help stamp out counterfeit and non-compliant equipment.

Lizzie, who is also a Quality Assurance Auditor for the National Examining Board of Dental Nurses (NEBDN), was awarded $£ 500$ to spend with a BDIA member of her choice. She commented: 'Seeing the fake equipment next to the real thing definitely makes you think about where the products come from and how important it is to purchase quality equipment from a reputable supplier in order to safely protect users and patients'.

The CSIDI campaign continues to highlight the danger of counterfeit and non-compliant dental equipment and the risk involved in purchasing from unknown sources.

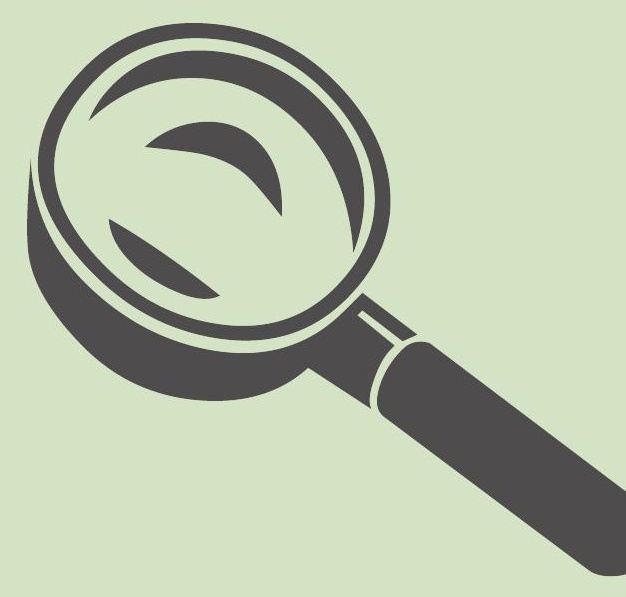

